\title{
Mental State Talk Structure in Children's Narratives: A Cluster Analysis
}

\author{
Giuliana Pinto, ${ }^{1}$ Caterina Primi, ${ }^{2}$ Christian Tarchi, ${ }^{1}$ and Lucia Bigozzi ${ }^{1}$ \\ ${ }^{1}$ Department of Education and Psychology, University of Florence, Florence, Italy \\ ${ }^{2}$ NEUROFARBA, University of Florence, Florence, Italy \\ Correspondence should be addressed to Christian Tarchi; christian.tarchi@gmail.com
}

Received 22 January 2017; Accepted 12 March 2017; Published 21 March 2017

Academic Editor: Randal X. Moldrich

Copyright (c) 2017 Giuliana Pinto et al. This is an open access article distributed under the Creative Commons Attribution License, which permits unrestricted use, distribution, and reproduction in any medium, provided the original work is properly cited.

\begin{abstract}
This study analysed children's Theory of Mind (ToM) as assessed by mental state talk in oral narratives. We hypothesized that the children's mental state talk in narratives has an underlying structure, with specific terms organized in clusters. Ninety-eight children attending the last year of kindergarten were asked to tell a story twice, at the beginning and at the end of the school year. Mental state talk was analysed by identifying terms and expressions referring to perceptual, physiological, emotional, willingness, cognitive, moral, and sociorelational states. The cluster analysis showed that children's mental state talk is organized in two main clusters: perceptual states and affective states. Results from the study confirm the feasibility of narratives as an outlet to inquire mental state talk and offer a more fine-grained analysis of mental state talk structure.
\end{abstract}

\section{Introduction}

Theory of Mind (ToM) is "the recognition of one's and others' affective and epistemic mental states as the psychological causes and motives underlying behaviours (p. 1)" [1]. The strict interconnection between language and ToM has led scholars to use children's mental state talk as an indicator of their ability to understand others' mental states [2-6], with narratives providing an ideal inquiry context [6]. However, research has neglected to explore children's mental state talk with a structural approach, to identify whether mental state terms are organized together or, conversely, are independent from each other. This study explored the children's mental state talk in narratives through a cluster analysis, to determine if children's mental state talk is structurally organized.

Mental state talk is defined as the set of terms used by people to attribute physiological (e.g., being hungry), perceptual (e.g., see), willing (e.g., desire), emotional (e.g., anger), cognitive (e.g., knowing), moral (e.g., judge), and sociorelational (e.g., helping) state to others [7, 8]. Although, mental state talk and ToM cannot be considered perfectly overlapping constructs, there are more similarities than differences between these two concepts [2,9]. Several studies have validated mental state talk as a reliable indicator of ToM by finding a significant correlation with standardized measures of ToM (e.g., false belief task, see [10, 11]). As such, mental state talk was implemented to measure several aspects of ToM, including maternal mind-mindedness [12] and autism [13-15] and as evidence to ToM in several contexts, including mother-child conversations [16] and peer conversations [17]. Some authors also believe that in certain contexts mental state talk is a stronger indicator of ToM than more traditional assessment of ToM [18]. Mental state talk is a more ecological instrument as it can be identified within children's spontaneous oral and written production. It widens the range of mental states that can be identified and analysed (e.g., desires and feelings, beside the cognitive-related aspects of ToM) [6].

Narratives represent an ideal and ecologically valid context to study ToM, as they require children to integrate socialcognitive, semantic, syntactic, pragmatic, and metacognitive knowledge [19]. Through narratives, children can develop, practice, and redescribe their ToM [6, 20-22]. Narratives are generally based on a conventional macrostructure, which includes initiating events, several interlinked episodes, goaldirected actions, internal responses, and a final resolution; see 
story-grammar approach $[23,24]$. As such, children need an advanced ToM to implement mental state talk in their narratives and centre them around a protagonist's intentions and subsequent actions [25]. Narrative is also a form of reflective thinking, as it reveals people's understanding of their own and other people's mental states [1]. There is a general consensus that the ability to tell narratives is related to sociocognitive, linguistic, and cognitive skills [26-28]. Indeed, for listeners to appreciate the full extent of a narrative's meaning, the teller needs to include in it the perspectives of multiple story characters [29]. Through narratives, when coordinating the different point of view of the characters involved, children can practice and develop perspective-taking skills, which are strictly associated with ToM [30]. As such, narratives provide children with a unique context to coordinate and organize several mental worlds [29].

A few studies have explored whether children present higher levels of first-order ToM when assessed through a narrative task as compared with vignette tasks as it is often the case with standard tests of first-order ToM [31-33]. However, these studies reported contradictory findings. Lewis et al. [31] and Szarkowicz [33] found that children understood false belief better during the narrative task than during the traditional false belief task, but Olver and Ratner [32] found that preschoolers' understanding of false beliefs through story telling was about the same as when measured on standard laboratory false belief tasks. Overall, narratives provide a good context to test children's ToM, especially at younger ages. Indeed, the false belief task requires more than just ToM to pass [34], and Lewis et al. [31] showed that children who had failed a traditional task succeeded if they narrated the book version back to the experimenter, particularly if they were fluent in their story recall.

Studies on the link between ToM and narrative production provide a further support to the hypothesis that mental state talk and narratives are associated. Most of such studies have explored autistic children, because of their difficulties in language and communication as well as ToM skills. In general, autistic children do not show significant differences in mental state talk in narratives than their normally developing peers $[13,35]$. Notwithstanding this similarity in mental state talk, autistic children appear to have more difficulties in creating cause-effect relationship about the characters' feelings [36]. Finally, few studies have also explored the relationship between ToM and narrative production also in normally developing children. Symons et al. [5] showed that 5- to 7year-old children who used more mental state terms in their narrative productions had also better performances in ToM standardized tasks, after controlling for the effects of age and language skills. Guajardo and Watson [20] found that preschoolers' performances in ToM standardized tests improved significantly as a result of a school-based storytelling intervention.

Mental state talk [37] and narrative competence [38, 39] develop during infancy and early childhood. Although children reach advance level in both construct once in primary school, also at the kindergarten level children are able to understand narratives through their mental state talk [25], as a result of the high rates of mental state terms included in children's books [40], as well as joint reading practices [41]. However, mental state talk has traditionally being studied in two main ways, either in terms of the specific categories, originally proposed by Bretherton and Beeghly [7], or as an aggregated score. Instead, to the best of our knowledge, the structure of mental state talk is unexplored. We wonder whether mental state terms are grouped in macrocategories, rather than working independently. This data could also suggest the existence of a structure in ToM too. Some indications in this sense derive from the literature on mental state talk development: not only the frequency of mental state terms increase, but also the qualitative use of such terms changes [42]. For instance, terms like "knowing" and "thinking" are used in a way that is progressively more sophisticated from 10 through 15 years of age (e.g., to plan activities or metacognitively reflect) [43].

This study analysed children's mental state talk in narratives in the last year of kindergarten. Prior studies have suggested that mental state talk is a reliable indicator of children's mental talk and that narratives provide an ideal outlet to study children's spontaneous production of mental state talk. In this study we analyse whether mental state terms are independent from each other or conversely whether mental state talk has an underlying structure, in which terms are organized and clustered together. ToM greatly develops during preschool and school years [37, 44], as well as the relationship between ToM and language [45]. To control for this effect, we measured children's mental state talk in narratives twice in a school year and verified the stability of mental state talk. In our study, we used cluster analysis to verify whether mental state terms are all on the same level, or whether it is possibly to identify a structure within mental state talk. The purpose of cluster analysis is to place objects into groups, suggested by the date, not defined a priori, such that objects in a cluster tend to be similar and objects in different clusters tend to be dissimilar.

\section{Method}

2.1. Participants. Ninety-eight children participated in this study (49 females and 49 males). On average, children were 5.4 years old in November (age range $=5.0-5.9$ years old) and 6.0 years old in June (age range $=5.5-6.6$ ). Participants were randomly selected from a larger sample of 335 children attending the last year of kindergarten in several schools located in a predominantly middle-class area on the outskirts of Florence, Italy. At the time of the study, no participant was diagnosed with a physical or mental disability, nor was included in a diagnostic process, or identified by the teachers as having special educational needs. Parents and school authorities, as well as the children themselves, gave consent to participate in the study.

In the Italian educational system, children typically start kindergarten at the age of three and finish it when they are five. Children then start elementary school when they are six years old. The school year begins in mid-September and ends in mid-June. All the participating kindergartens were following the national guidelines issued by the Ministry of Education which were valid at the time of the study. 
TABLE 1: Description of the coding system for mental state talk (adatpted from Bretherton and Beeghly, 1982).

\begin{tabular}{lll}
\hline Category & Description & Examples \\
\hline $\begin{array}{l}\text { Perceptual and } \\
\text { physiological states }\end{array}$ & $\begin{array}{l}\text { Terms representing perceptual and physiological } \\
\text { states that might influence our behavior (such as } \\
\text { hunger and thirst) and describe how we perceive } \\
\text { the world }\end{array}$ & $\begin{array}{l}\text { Being hungry, eating, drinking, being born, being } \\
\text { ill, watching, listening, smelling, recognizing, } \\
\text { feeling bad, felling hot/cold, noticing }\end{array}$ \\
Emotional state & Terms describing our feelings and emotions & $\begin{array}{l}\text { Happy, pretty, nice, kiss, caressing, cuddle, hug, } \\
\text { like, caring, sad, angry, annoyed, ugly, scared, } \\
\text { crying, screaming, getting bored, worrying, } \\
\text { complaining } \\
\text { Willing, can, hoping, achieving, letting, trying, } \\
\text { looking for, ordering } \\
\text { Killingness state }\end{array}$ \\
Terms describing what we want to achieve and do & $\begin{array}{l}\text { Knowing, thinking, understanding, } \\
\text { remembering, forgetting, clever, paying attention, } \\
\text { true, false } \\
\text { Terms representing what we cognitively think }\end{array}$ & $\begin{array}{l}\text { Good, having to, reprimanding, promising, giving } \\
\text { thanks, recommending, obeying, joking, helping, } \\
\text { alone, becoming friends, abandoning, tricking }\end{array}$ \\
\hline
\end{tabular}

Narratives are part of children's daily routines in school; thus they represent an ecologically valid measure in this study.

2.2. Procedure. Children were tested individually outside their classroom, in a quiet room within their school. Once in the room, the experimenter asked each child to make up and tell a story. All narratives were recorded and transcribed. Children were asked to tell a story twice, at the beginning of the school year (November) and at the end of the school year (June). In total, we collected 196 narratives, two for each participant. The data collection took place in agreement with the school and following the requirements of privacy and informed consent requested by Italian law (Legislative Decree DL-196/2003). Regarding the ethical standards for research, the study referred to the last version of the Declaration of Helsinki [46]. The present study was approved by the Ethical Committee of the Department of Psychology at the University of Florence, Italy.

2.3. Coding System. Mental state talk was analysed by identifying terms and expressions referring to mental states (adapted from [7]). In particular, we identified the following categories: perceptual-physiological states, emotional states, willingness states, cognitive states, and moral and sociorelational states (see Table 1). Two independent judges coded the narratives in terms of mental state talk. Interrater agreement scores were acceptable for all mental state categories $(k>$ $0.70)$.

2.4. Data Analysis. To control whether children's mental state talk production in narratives changes within the school year, we run a paired-sample $t$-test on children's narrative produced at the beginning versus the end of the school year. To identify a structure within children's mental state talk production and verify whether category terms tend to group together, we run a cluster analysis with Ward method (Squared Euclidean distance) through SPSS software. To determine the number of clusters, we examined the dendrogram that graphically showed how the clusters are merged and allowed to identify the appropriate number of clusters.

\section{Results}

Descriptive results are presented in Table 2, frequencies of subjects using a specific mental state talk and mean and standard deviations of mental state talk.

Overall, the most frequent mental state terms used by children were physiological and perceptual terms, followed by willingness, moral, and cognitive terms. Children's mental state talk was overall stable through the school year, except for two categories that increased over time: positive emotion states and sociorelational states.

According to the paired-sample $t$-test, there was not a significant development in the quantity of mental state talk produced from the beginning through the end of the school year $(p>0.05)$. Thus, mental state talk appeared to be a stable variable within the school year. According to the cluster analysis with Ward method conducted on children's mental state talk production, two main clusters emerged, one mainly characterized by perceptual states and the other by affective states (see Figure 1).

When observing the content of the stories underlining these two clusters, we could identify two different typologies: narratives centred on actions and narratives centred on feelings. An example of action-centred narrative is as follows:

Once upon a time there was Cecco Volta, who was going to work because he had to build a school. Then, when he went to eat a piglet arrived, it was hungry and the other ones not. Come on Pietro, let us climb on the bulldozer! But he did not let them climb on it. He had to dig and broke the ground, and then they had to finish the job. He was put outside to sleep in the excavator's thing. 
TABLE 2: Frequencies of subjects and use of mental state talk categories in the two assessments ( $n$, mean \pm standard deviation).

\begin{tabular}{lcccc}
\hline & \multicolumn{2}{c}{ Beginning of the school year } & \multicolumn{2}{c}{ End of the school year } \\
& $n$ & $\mathrm{M} \pm \mathrm{SD}$ & $n$ & $\mathrm{M} \pm \mathrm{SD}$ \\
\hline Physiological states & 63 & $2.27 \pm 2.27$ & 50 & $1.83 \pm 2.24$ \\
Perceptual states & 49 & $1.35 \pm 2.50$ & 39 & $0.94 \pm 1.20$ \\
Positive emotion states & 29 & $0.50 \pm 1.00$ & 11 & $0.76 \pm 1.09$ \\
Negative emotions states & 12 & $0.21 \pm 0.76$ & 39 & $0.21 \pm 0.76$ \\
Willingness states & 33 & $0.65 \pm 1.19$ & 34 & $0.63 \pm 0.96$ \\
Cognitive states & 32 & $0.59 \pm 1.20$ & 34 & $0.53 \pm 0.90$ \\
Moral states & 29 & $0.75 \pm 1.89$ & 18 & $0.59 \pm 1.06$ \\
Sociorelational states & 15 & $0.24 \pm 0.62$ & & $0.34 \pm 0.85$ \\
\hline
\end{tabular}

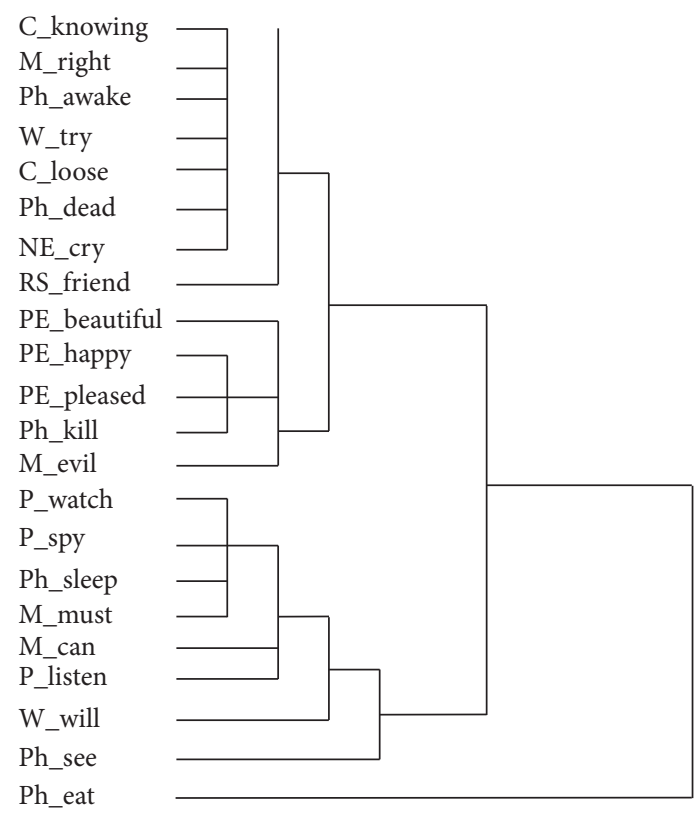

Figure 1: Clusters of mental state talk. Note. Ph: physiological state; P: perceptual state; PE: positive emotion state; NE: negative emotion state; W: willingness state; C: cognitive state; M: moral state; and RS: relationship state.

An example of feeling-centred narrative is as follows:

Once upon a time there was a child who lived in a far far away house with the father, the mother, and the little sister, whose name was Emily. The child's name was Marco, he fought with Emily and hit her, then the little sister started crying. The mother scolded Marco and said, "Go to your room, and apologize to your sister!" Marco apologized to the sister, and made peace with his mother.

\section{Discussion}

This study analysed children's mental state talk in narratives in the last year of kindergarten. Firstly, our results indicate that children' mental state talk production within their narratives appears to be quite stable across the school year. This analysis provides a baseline measure for mental state talk development within the 5 years of age through a more fine-grained analysis, considering that most of the studies conducted on children's mental state development have focused on more drastic transitions, such as the one from kindergarten to primary school. The frequency of mental state talk was similar in the two assessments suggesting that children's mental state talk development is characterized by a plateaux moment at the end of kindergarten. Or, alternatively, mental state talk development might have been constrained by children's narrative competence. Past studies on narrative competence development have emphasized that at 5 years of age, children storytelling skills are still limited and do not increase much before the onset of schooling [47, 48]. For instance, they provide some details on the characters' thoughts and goals [49] but do not elaborate much about the characters' mental states or problem complications [50].

According to the results from the cluster analysis, two clusters emerged, one representing narratives with mainly perceptual mental state terms (action-centred narratives) and the other by narrative with mainly affective mental state terms (emotion-centred narratives). An action-centred narrative mainly focuses on mental states describing the relationship between the characters and the world, such as perceptual or physiological states. Conversely, an emotioncentred narrative focuses on the characters' internal reaction and on their influence on the behaviour. Most of the actioncentred narratives described the adventures of characters. As such, children mainly use mental states that describe the relationship between the individual and the world, that is, perceptual and physiological terms. Conversely, in emotioncentred narratives, children focus more on the characters' internal reactions, on their emotions, and their effect on behaviour. At this age, the ability to integrate in their narratives the complex interplay between emotional, motivational, and cognitive components that causes actions and events to happen is still emerging. However, our data support the hypothesis that children might already be able to use mental state talk to characterize their narratives.

Results of the cluster analysis suggest a qualitative interpretation of children's mental state talk. The two clusters describe aggregation of narratives that differ in types of mental state terms included. In the action-centred narratives, 
the plot is substantially grounded in the main characters' perceptions and physiological needs. In the emotion-centred narratives instead the plot is guided by what the main characters think and wish, revealing a more cognitive and emotive mind.

In conclusion, this study offers a fine-grained analysis of children's mental state talk in narratives. Mental state talk was organized into two main constructs, which suggests that this construct might be more complex and articulated than prior studies have claimed. Similarly to what happened with the construct of metacognition, we speculate that mental state talk (and ToM) might be characterized by two components, one more complex and focused on deep motives driving behaviours (emotions) and one more superficial and focused on shallow motives driving behaviours (perceptions). Borrowing the iceberg metaphor, children's interpretation of other people's behaviour might have first a superficial level, in which actions are simply seen in light of perceptions ("I eat because I am hungry") and a second, deeper level, in which actions are seen as an outcome of an internal elaboration driven by emotions ("My mom feels bad, and I need to apologize").

This study was affected by a few limitations. Generalization of results is limited by the research design of this study, in particular using oral narratives. Once in primary school, there is a discontinuity in children's narrative competence, when writing is introduced [39], which could affect the relationship between narrative and ToM. Moreover, narratives are culture-bound [51], age-bound [52], and gender-bound [53]. Consequently, the association between narrative content and mental state talk might change as a function of these variables. A further limitation relates to the statistical method chose to analyse data. Cluster analysis refers to a class of data reduction methods for observations into homogeneous groups that differ from each other. Since cluster analysis is an explorative analysis it is necessary to confirm these results in others studies. The findings reported in this article could be also important in providing the foundations for future research on mental state talk structure in narratives. Several studies have suggested the potential positive effects of narrative on children's ToM $[5,13,20,31]$. This study suggests showing how a specific type of narrative is associated with certain mental state terms. Because no previous study had explored this association, our research design was exploratory, not allowing us to draw more solid conclusions. Future studies should confirm our results by quantitatively assessing and categorizing narrative content of stories and exploring the association with the clusters of mental state talk.

\section{Conflicts of Interest}

The authors declare that there are no conflicts of interest regarding the publication of this paper.

\section{Acknowledgments}

The authors would like to thank Elisa Faso for her help with data collection.

\section{References}

[1] A. Antonietti, E. Confalonieri, and A. Marchetti, "Introduction: do metarepresentation and narratives play a role in reflective thinking?" in Reflective Thinking in Educational Settings: A Cultural Framework, A. Antonietti, E. Confalonieri, and A. Marchetti, Eds., pp. 1-14, Cambridge University Press, Cambridge, UK, 2014.

[2] A. Antonietti, O. Liverta-Sempio, and A. Marchetti, Theory of Mind and Language in Developmental Contexts, Springer Science + Business Media, Inc., New York, NY, USA, 2006.

[3] J. W. Astington and J. A. Baird, Why Language Matters for Theory of Mind, Oxford University Press, New York, NY, USA, 2005.

[4] J. Dunn and C. Hughes, "Young children's understanding of emotions within close relationships," Cognition and Emotion, vol. 12, no. 2, pp. 171-190, 1998.

[5] D. K. Symons, C. C. Peterson, V. Slaughter, J. Roche, and E. Doyle, "Theory of mind and mental state discourse during book reading and story-telling tasks," British Journal of Developmental Psychology, vol. 23, no. 1, pp. 81-102, 2005.

[6] G. Pinto, C. Tarchi, B. Accorti Gamannossi, and L. Bigozzi, "Mental state talk in children's face-to-face and telephone narratives," Journal of Applied Developmental Psychology, vol. 44, pp. 21-27, 2016.

[7] I. Bretherton and M. Beeghly, "Talking about internal states: the acquisition of an explicit theory of mind," Developmental Psychology, vol. 18, no. 6, pp. 906-921, 1982.

[8] D. K. Symons, "Mental state discourse, theory of mind, and the internalization of self-other understanding," Developmental Review, vol. 24, no. 2, pp. 159-188, 2004.

[9] A. Valle, D. Massaro, I. Castelli et al., "Promoting mentalizing in pupils by acting on teachers: preliminary Italian evidence of the 'Thought in Mind' project," Frontiers in Psychology, vol. 7, article 1213, 12 pages, 2016.

[10] C. C. Peterson and V. P. Slaughter, "Telling the story of theory of mind: deaf and hearing children's narratives and mental state understanding," British Journal of Developmental Psychology, vol. 24, no. 1, pp. 151-179, 2006.

[11] B. A. Gamannossi and G. Pinto, "Theory of mind and language of mind in narratives: developmental trends from kindergarten to primary school," First Language, vol. 34, no. 3, pp. 262-272, 2014.

[12] E. Meins, C. Fernyhough, R. Wainwright, M. Das Gupta, E. Fradley, and M. Tuckey, "Maternal mind-mindedness and attachment security as predictors of theory of mind understanding," Child Development, vol. 73, no. 6, pp. 1715-1726, 2002.

[13] L. Capps, M. Losh, and C. Thurber, "“'The frog ate the bug and made his mouth sad": narrative competence in children with autism," Journal of Abnormal Child Psychology, vol. 28, no. 2, pp. 193-204, 2000.

[14] F. G. E. Happé, "An advanced test of theory of mind: understanding of story characters' thoughts and feelings by able autistic, mentally handicapped, and normal children and adults," Journal of Autism and Developmental Disorders, vol. 24, no. 2, pp. 129-154, 1994.

[15] H. Tager-Flusberg, "Autistic children's talk about psychological states: deficits in the early acquisition of a theory of mind," Child Development, vol. 63, no. 1, pp. 161-172, 1992.

[16] T. Ruffman, L. Slade, and E. Crowe, "The relation between children's and mothers' mental state language and theory-ofmind understanding," Child Development, vol. 73, no. 3, pp. 734-751, 2002. 
[17] C. Hughes and J. Dunn, "Understanding mind and emotion: longitudinal associations with mental-state talk between young friends," Developmental Psychology, vol. 34, no. 5, pp. 1026-1037, 1998.

[18] H. Wimmer and J. Perner, "Beliefs about beliefs: representation and constraining function of wrong beliefs in young children's understanding of deception," Cognition, vol. 13, no. 1, pp. 103$128,1983$.

[19] C. Fernández, "Mindful storytellers: emerging pragmatics and theory of mind development," First Language, vol. 33, no. 1, pp. 20-46, 2011.

[20] N. R. Guajardo and A. C. Watson, "Narrative discourse and theory of mind development," Journal of Genetic Psychology, vol. 163, no. 3, pp. 305-325, 2002.

[21] A. Karmiloff-Smith, Beyond Modularity: A Developmental Perspective on Cognitive Science, MIT Press, Cambridge, Mass, USA, 1995.

[22] A. Marchetti, F. Baglio, I. Costantini et al., "Theory of mind and the whole brain functional connectivity: behavioral and neural evidences with the Amsterdam Resting State Questionnaire," Frontiers in Psychology, vol. 6, article 1855, 2015.

[23] N. L. Stein and C. G. Glenn, "An analysis of story comprehension in elementary school children," in The Developmental Psychology of Time, W. Friedman, Ed., pp. 255-282, Academic Press, New York, NY, USA, 1982.

[24] J. A. Dimino, R. M. Taylor, and R. M. Gersten, "Synthesis of the research on story grammar as a means to increase comprehension," Reading and Writing Quarterly, vol. 11, no. 1, pp. 53-72, 1995.

[25] J. Pelletier and R. Beatty, “Children's understanding of Aesop's fables: relations to reading comprehension and theory of mind," Frontiers in Psychology, vol. 6, article 1448, 2015.

[26] P. Zanchi, L. Zampini, M. Fasolo, and L. D'Odorico, "Syntax and prosody in narratives: a study of preschool children," First Language, vol. 36, no. 2, pp. 124-139, 2016.

[27] J. W. Astington, "Narrative and the child's theory of mind," in Narrative Thought and Narrative Language, B. K. Britton and A. D. Pellegrini, Eds., pp. 151-171, Lawrence Erlbaum Associates, Hillsdale, NJ, USA, 1990.

[28] H. Tager-Flusberg, “'Once upon a ribbit': stories narrated by autistic children," British Journal of Developmental Psychology, vol. 13, no. 1, pp. 45-59, 1995.

[29] K. Nelson, "Narrative practices and folk psychology: a perspective from developmental psychology," Journal of Consciousness Studies, vol. 16, no. 6-8, pp. 69-93, 2009.

[30] B. Liddle and D. Nettle, "Higher-order theory of mind and social competence in school-age children," Journal of Cultural and Evolutionary Psychology, vol. 4, no. 3, pp. 231-244, 2006.

[31] C. Lewis, N. H. Freeman, C. Hagestadt, and H. Douglas, "Narrative access and production in preschoolers' false belief reasoning," Cognitive Development, vol. 9, no. 4, pp. 397-424, 1994.

[32] R. R. Olver and N. K. Ratner, “Children's understanding of false beliefs in two contexts," Psychological Reports, vol. 75, no. 3, pp. 1136-1138, 1994.

[33] D. L. Szarkowicz, “'When they wash him they'll know he'll be Harry': young children's thinking about thinking within a story context," International Journal of Early Years Education, vol. 8, no. 1, pp. 71-81, 2010.

[34] P. Bloom and T. P. German, "Two reasons to abandon the false belief task as a test of theory of mind," Cognition, vol. 77, no. 1 , pp. B25-B31, 2000.
[35] M. Losh and L. Capps, "Narrative ability in high-functioning children with autism or Asperger's Syndrome," Journal of Autism and Developmental Disorders, vol. 33, no. 3, pp. 239-251, 2003.

[36] H. Tager-Flusberg and K. Sullivan, "Attributing mental states to story characters: a comparison of narratives produced by autistic and mentally retarded individuals," Applied Psycholinguistics, vol. 16, no. 3, pp. 241-256, 1995.

[37] H. M. Wellman, D. Cross, and J. Watson, "Meta-analysis of theory-of-mind development: the truth about false belief," Child Development, vol. 72, no. 3, pp. 655-684, 2001.

[38] G. Pinto, C. Tarchi, and L. Bigozzi, "Development in narrative competences from oral to written stories in five- to seven-yearold children," Early Childhood Research Quarterly, vol. 36, pp. 1-10, 2016.

[39] G. Pinto, C. Tarchi, and L. Bigozzi, “The relationship between oral and written narratives: a three-year longitudinal study of narrative cohesion, coherence, and structure," British Journal of Educational Psychology, vol. 85, no. 4, pp. 551-569, 2015.

[40] J. R. Dyer, M. Shatz, and H. M. Wellman, "Young children's storybooks as a source of mental state information," Cognitive Development, vol. 15, no. 1, pp. 17-37, 2000.

[41] J. E. Adrian, R. A. Clemente, L. Villanueva, and C. Rieffe, "Parent-child picture-book reading, mothers' mental state language and children's theory of mind," Journal of Child Language, vol. 32, no. 3, pp. 673-686, 2005.

[42] A. M. Scopesi, A. M. Rosso, C. Delfante, and S. Pangallo, "Lessico psicologico e abilità di mentalizzazione nella preadolescenza," Ricerche di Psicologia, vol. 3, pp. 377-396, 2010.

[43] J. R. Booth and W. S. Hall, "Role of the cognitive internal state lexicon in reading comprehension," Journal of Educational Psychology, vol. 86, no. 3, pp. 413-422, 1994.

[44] L. Bigozzi, A. Di Cosimo, and G. Vettori, "Appearances are deceiving: observing the world as it looks and how it really is-theory of mind performances investigated in 3-, 4-, and 5-year-old children," Child Development Research, vol. 2016, Article ID 5270924, 10 pages, 2016.

[45] J. W. Astington and J. M. Jenkins, "A longitudinal study of the relation between language and theory-of-mind development," Developmental psychology, vol. 35, no. 5, pp. 1311-1320, 1999.

[46] World Medical Association, Declaration of Helsinki: Ethical Principles for Medical Research Involving Human Subjects, World Medical Association, Fortaleza, Brazil, 2013, http://www.wma .net/en/30publications/10policies/b3/index.html.

[47] C. Peterson and A. McCabe, Developmental Psycholinguistics. Three Ways of Looking at a Child's Narrative, Plenum Press, New York, NY, USA, 1983.

[48] L. Mäkinen, S. Loukusa, L. Nieminen, E. Leinonen, and S. Kunnari, "The development of narrative productivity, syntactic complexity, referential cohesion and event content in four- to eight-year-old Finnish children," First Language, vol. 34, no. 1, pp. 24-42, 2014.

[49] N. L. Stein and C. G. Glenn, "An analysis of story comprehension in elementary school children," in New Directions in Discourse Processing, N. O. Freedle, Ed., pp. 53-120, Ablex, Norwood, NJ, USA, 1979.

[50] R. J. Beck and K. A. Clarke-Stewart, "Improving 5-year-olds' narrative recall and comprehension," Journal of Applied Developmental Psychology, vol. 19, no. 4, pp. 543-569, 1998.

[51] V. John-Steiner and C. Panofsky, "Narrative competence: crosscultural comparisons," Journal of Narrative and Life History, vol. 2, no. 3, pp. 219-233, 1992. 
[52] S. P. Suggate, E. A. Schaughency, and E. Reese, "The contribution of age and reading instruction to oral narrative and prereading skills," First Language, vol. 31, no. 4, pp. 379-403, 2011.

[53] E. S. Richner and A. Nicolopoulou, "The narrative construction of differing conceptions of the person in the development of young children's social understanding," Early Education \& Development, vol. 12, no. 3, pp. 393-432, 2001. 


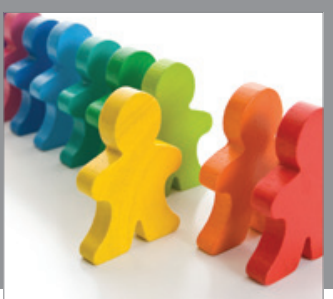

Autism

Research and Treatment
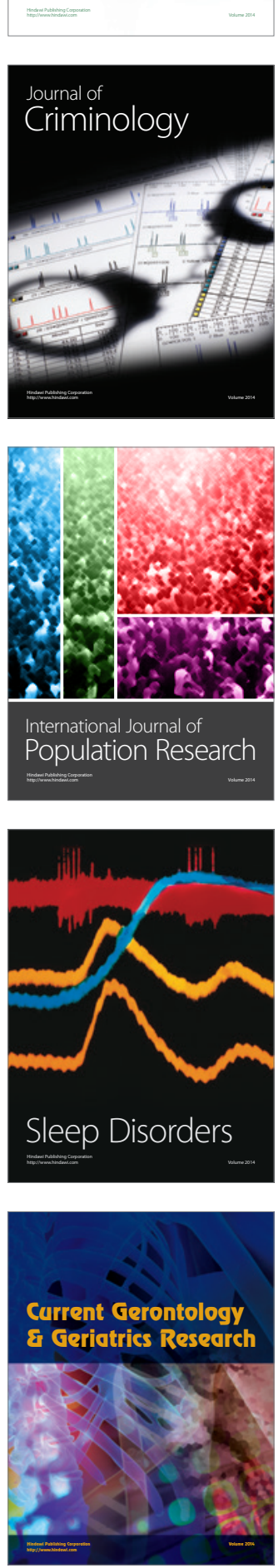

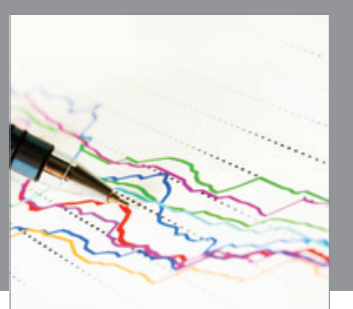

Economics

Research International
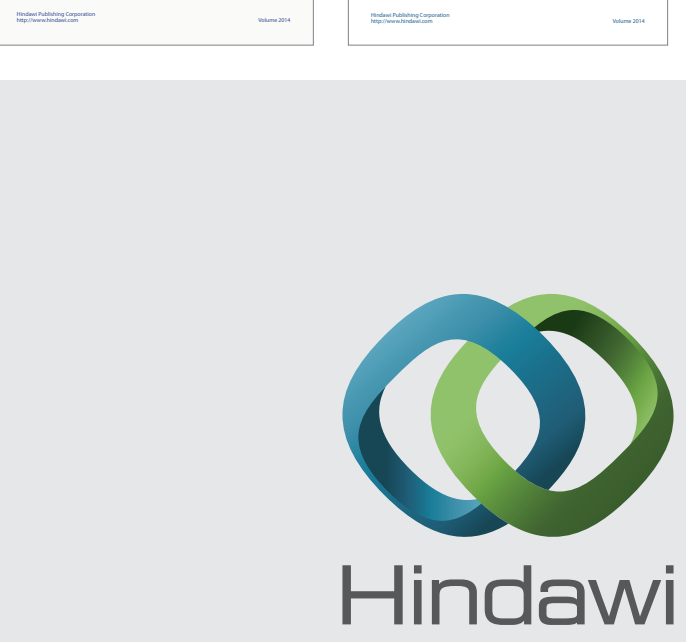

Submit your manuscripts at

https://www.hindawi.com
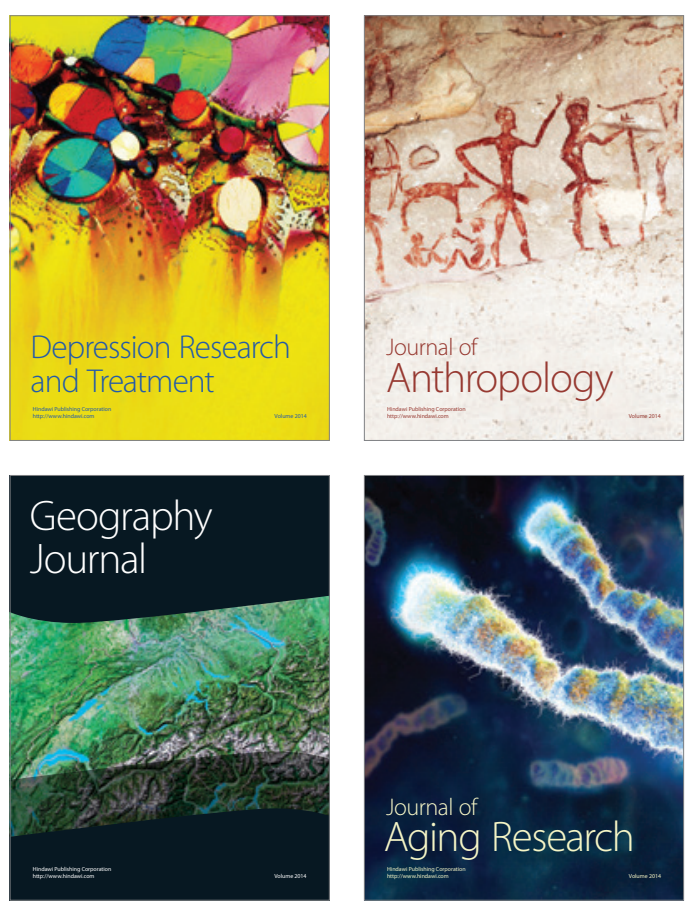
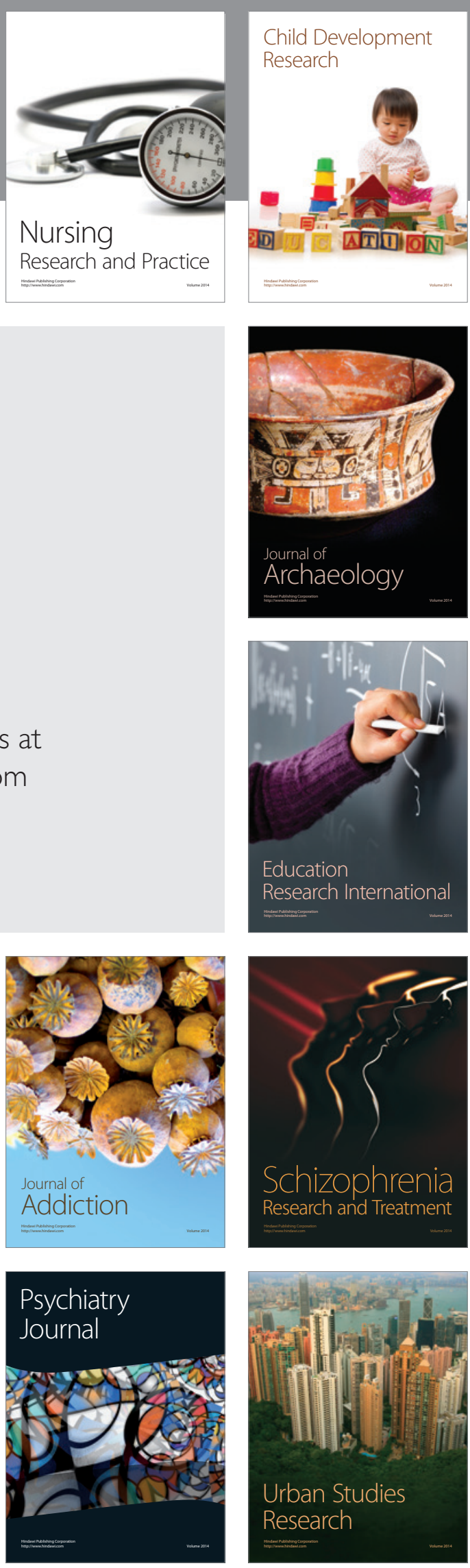